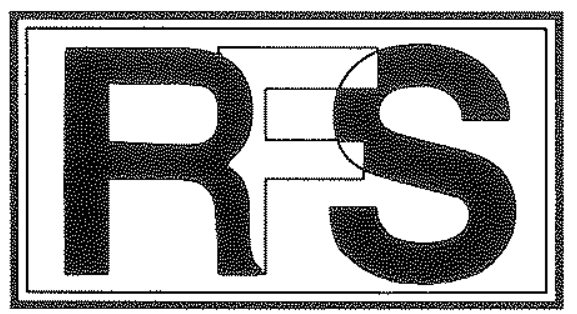

Revista de Fomento Soclal, 48 (1993), 205-226

\title{
Estructuras Sociales y Estructuras de poder en América Latina (1)
}

El autorse sitúa en una perspectiva de análisis estructural no funcionalista. Desde ella analiza la articulación entre la institución básica del poder -el estado- y la sociedad. Pasa revista a cuatro etapas de esa articulación en América Latina. la dominación oligárquica, el populismo, las dictaduras militares y las recientes democracias. En bodas ellas, dicha articulación tiene dos rasgos condicionantes: la desestructuración de la sociedad civil y el intento de conformar un estado fuerte. El reto precisamente de las actuales y débiles dentocracias es compaginar esa necesidad de un estado decisionista e intervencionista con fórmulas que garanticen el respeto de los derechos humanos y los cauces institucionales de expresión de la voluntad popular.

Francisco ENTRENA DURAN

$\left.{ }^{*}\right)$ Profesor de Sociología de la Universidad de Granada.

(1) Tex to de la ponencia presentada al IV Congreso Nacional de Sociologia, celebrado en Madrid en septiembre de 1992. Agradezco al Consejo de Redacción de la Revista de Fomento Social la publicación de este texto, así como las acertadas sugerencias de modificación de la estructura del mismo que se me han hecho, por parte de dicho Consejo. 


\section{Consideractones Preliminares}

Como es usual con los términos que se ponen de moda, la palabra estructura contiene unos significados conceptuales escasamente precisos. El ámbito de aplicación de dicho vocablo no se restringe únicamente al campo de las Ciencias Humanas y Sociales, sino que el mismo se ha incorporado a las jergas profesionales de los especialistas más dispares. En este sentido, por citar algunos ejemplos, un botánico nos hablará de las estructuras de una flor, un edafólogo de la estructura del suelo, un quimico de las estructuras moleculares, etc., etc.. Resulta por lo tanto obligado, antes de entrar en la materia objeto de estas argumentaciones, realizar algunas precisiones acerca de lo que en las mismas se entenderá como estructura social.

En el marco concreto del análisis sociológico, el empleo de la palabra estructura se justifica por el propósito de aplicar una metodología para enfrentarse al estudio de la realidad social, considerando a ésta como una totalidad de partes interdependientes e interrelacionadas entre sí. Totalidad estructurada que no es entendida de la misma forma por todos los sociólogos que emplean el término estructura social. Creo oportuno destacar aqui dos maneras diferenciadas de concebir dicho término: a) la que tiende a identificarlo con la estructura institucional y simbólico-normativa, a través de la que se representa y trata de reproducirse el orden social y el paradigma ideal del mismo en la colectividad que en cada caso se estudia; $y, b$ ) la que, por contra, considera la estructura como un mero modelo teórico específico, mediante el que el investigador se enfrenta, en cada caso concreto, al análisis de determinados aspectos del inagotable y cambiante entramado de relaciones, económicas, políticas y propiamente sociales de cualquier sociedad.

El análisis estructural-funcional encajaría dentro de la primera modalidad de entender el término estructura, ya que en el funcionalismo predomina una inclinación tendente a dejar de lado que toda ordenación social es una realidad provisional y dinámica, por lo que, de hecho, esta corriente del pensamiento sociológico suele centrarse, preferentemente, en el estudio del funcionamiento y la finalidad de los marcos institucionales y simbólico-normativos del orden. social vigente, que se concibe como algo permanente $y / o$ ahistórico.

Por mi parte considero que, ante la inconmensurabilidad de la realidad social y ante la naturaleza circunstancial y cambiante de la misma, la alternativa más 
sensata es adoptar, en cada caso de estudio especifico, un concepto de estructura que permita poner en práctica una estrategia analitica en la que, a la vez que se reconozcan los modestos límites de todo conocimiento humano respecto a la inabarcable totalidad, continuo cambio y consiguiente provisionalidad histórica de toda formación social, se propicie la construcción de un modelo teórico adecuado analiticamente para caracterizar el fenómeno que se trata de estudiar. En este caso, dicho fenómeno es las diversas formas características de estructuración del poder estatal en Latinoamérica y su relación dialéctica, de mutua interinfluencia e interdependencia, con las estructuras sociales de la región. Para ello, he creído conveniente concebir la estructura social como un modelo global, en el que se tratan de establecer las interrelaciones entre los niveles económico-sociales, institucionales y simbólico-legitimadores de la sociedad. De este modo, el poder, que aquí se considera incluido dentro del nivel institucional, será analizado como una parte intrinseca de la estructura de la sociedad, como un elemento conformador/conformado de/por la misma, cuya lógica de funcionamiento, por lo tanto, guarda una estrecha relación de correspondencia con la lógica de articulación práctica y de legitimación teórica del discurso del poder sobre la sociedad.

$\mathrm{La}$ aplicación del modelo precedente de estructura social me sirve de base para pasar una rápida y somera revista a algunas de las fórmulas más significativas de articulación y delegitimación del poder en la realidad latinoamericana, tales como la estructuración del poder en la etapa de predominio del sistema oligárquico, en el populismo, en los últimos regímenes militaristas o en los actuales sistemas democráticos. La superficialidad, con la que se considerarán realidades sociopoliticas tan amplias como las que se acaban de mencionar, se debe, de una parte, a la exigencia de brevedad que me impone el, relativamente reducido, margen de espacio/tiempo de que dispongo y, de otra, al propósito de resaltar solamente los aspectos más fundamentales y pertinentes para mostrar la aplicación y verificación especifica del modelo teórico de análisis que he esbozado más arriba. Modelo, que creo necesario precisar que no se propone como objetivo adentrarse en el estudio exhaustivo de las numerosas y variadas configuraciones de poder $y / o$ regímenes políticos de Latinoamérica, ni tampoco afrontar un examen, en profundidad, de la diversidad y heterogeneidad de estructuras sociales existentes en dicha región. Ello, porque considero que ambos objetivos serían dificilmente abarcables en una exposición como la que 
me ocupa en esta ocasión. En concreto, la finalidad de dicho modelo es, básicamente, examinar y poner de manifiesto las peculiaridades de la forma particular en que, en América Latina, se lleva a cabo la vinculación entre estructuras sociales y estructuras de poder. Vinculación esta, que suele ser una constante característica de la generalidad de las sociedades. El grado de claridad, con que, en las argumentaciones posteriores, se consigan configurar los rasgos generales definitorios de la peculiaridad de inserción del poder en la sociedad latinoamericana, puede considerarse como un indicador adecuado para mostrar la capacidad explicativa y la utilidad analitica del modelo al que se está haciendo referencia.

\section{Las bases del poder oligárquico}

Hasta la sacudida política que se produjo en Latinoamérica, a raíz de la crisis económica de los años treinta, preponderó en la región el sistema de dominación oligárquico. La estructura social, sobre la que tal sistema de dominación se sustentaba, es caracterizada a continuación como una totalidad integrada por los tres niveles de análisis que se han propuesto anteriormente en las consideraciones preliminares. Tales niveles son: el económico-social, el institucional y el simbólico-legitimador.

a) Elnivel económico-social. La base de sustentación económico-social de la dominación oligárquica estaba en los latifundistas rurales y en los grandes propietarios mineros coaligados, a su vez, con los más importantes grupos de financieros y de comerciantes urbanos. Los vínculos de carácter personalista yf o de parentesco entre estos diversos sectores eran de una considerable magnitud, tal como se ha puesto de manifiesto por reiterados estudios al respecto, en los que se ha mostrado como un, considerablemente reducido, número de personas y/o de familias controlaba los resortes básicos del poder económico; de ahi, la caracterización de esta mođalidad de dominación como oligárquica. Es sabido que, en el interior de ese restringido conglomerado social que conformaba la oligarquía, las relaciones intemas entre los diversos grupos de parentesco o sectores que lo componían no siempre se llevaron a cabo en un clima de cordialidad, sino que, por contra, resul taron intensas y relativamente frecuentes las rivalidades intestinas y los conflictos de intereses. Ello estaba motivado, en gran medida, porque la diversificación estructural interna alcanzaba una 
considerable magnitud. En este sentido, resultó, usualmente, muy difícil establecer fórmulas de consenso entre los diferentes sectores oligárquicos, de cara a fijar las directrices de las políticas públicas a adoptar. Políticas que, obviamente, habían de afectar de modo muy distinto a los numerosos y diferentes contextos regionales existentes, cuyos intereses, por estar muy vinculados a los específicos recursos y a la característica especialización de su restringido marco local en el cultivo de productos agrarios para la exportación, eran notablemente dispares entre sí. La ausencia de un mercado nacional integrado, suplida por la modalidad de producción autárquica estructurada en torno a las grandes haciendas, constituía la característica y el condicionamiento fundamental del localismo regionalista y de la fragmentación de intereses que existían en la sociedad civil oligárquica.

b) El nivel institucional. La preponderancia del regionalismo localista en el período oligárquico determinó que, en líneas generales, la institucionalidad del Estado latinoamericano en esta etapa se asentara sobre una base estructural débil y fluctuante. Se trataba de un Estado excesivamente ligado a intereses sectoriam les y con un escaso, al mismo tiempo que poco efectivo, papel político y administrativo que, en definitiva, se reducía a poco más que a ser una prolongación del poder familístico de la oligarquía, constituyendo un instrumento de dominación al servicio de la misma. Prácticamente, las limitadas funciones del Estado se circunscribian sólo a las relaciones internacionales y a garantizar la seguridad de las fronteras, así como a la represión y a la salvaguardia del orden público interno, sobre todo, en los núcleos urbanos, en los que se hacía necesario contener la acción opositora de los grupos sociales emergentes que se situaban al margen del orden establecido por la oligarquía.

La escasa capacidad y la limitación del poder del Estado era tal que muchas veces éste no pudo cumplir de forma eficaz la que, por entonces, constituía su principal función; es decir, la tarea de arbitrar en los conflictos intraoligárquicos. Tarea esta, ante la que el poder estatal se encontraba sin recursos suficientes para imponer una solución a los distintos bandos contrincantes. En otras palabras, el Estado era débil porque sus medios de acción y sus mecanismos de coerción eran escasos y poco capacitados para imponerse sobre una heterogeneidad de fuerzas y de facciones de carácter caciquil y/o feudalizante, amparadas, especialmente, en los grandes propietarios territoriales, los que, con bastante frecuencia, eran también jefes militares que contaban con ejércitos particulares 
o que, eventualmente, recurrian a armar a sus peonadas, a los campesinos y/o a la gran cantidad de desposeídos y marginados que, por aquellas fechas, tanto proliferaban. Tales sectores marginales constituian una fuente de descontento social que fue reiteradamente utilizada por los caciques y caudillos regionales para generar movilizaciones o reconducir las mismas en su propio provecho.

c) El nivel simbólico-legitimador. Como es comúnmente sabido, pese a que, por lo general, los Estados latinoamericanos, durante el período al que se está haciendo referencia, adoptaron regímenes políticos de carácter liberal, lo cierto es que esto, usualmente, constituyó una mera fachada formal que encubría una situación de hecho fuertemente opresiva. En realidad, los sistemas liberales proporcionaron, en la practica, el contexto jurídico-ideológico sobre el que se efectuaron las reformas en el régimen de tenencia de la tierra, a partir de las que se hizo posible la desvinculación patrimonial de aquella y un notable proceso de engrandecimiento de los latifundios ya existentes, a la vez que de concentración de la propiedad agraria. Propiedad que ahora era entendida en el sentido capitalista del término. Lo que, en definitiva, conllevaron las distintas leyes reformadoras, que en este contexto se pusieron en práctica en Latinoamérica, fue la adaptación de las conđiciones de tenencia y de explotación de la propiedad rural a las exigencias de la economía agroexportadora que, como es conocido, constituyó una de las principales bases de sustentación del poder oligárquico. En razón de lo que se está diciendo, es comprensible que la aceptación colectiva y consiguiente legitimación social de las ideas liberales fuera muy escasa, por parte del grueso de la población latinoamericana de la época, sumida en el atraso, en la marginación y en el analfabetismo, impedida incluso de la posibilidad de votar a sus representantes por la imposición del sistema electoral censatario. En estas circunstancias, la ineludible apoyatura de la identidad colectiva en unos paradigmas de legitimidad social, no pudo llevarse a cabo para la mayor parte de los latinoamericanos de esos años, a través de su inserción en el sistema político estatal, dada la debilidad institucional, la naturaleza oligárquica del Estado y su escasa penetración en la sociedad y en la conciencia colectiva de la inmensa mayoria de la población. Población, que se desenvolvía en una situación que no favorecia el desarrollo de algo parecido a un "sentido de Estado" o una "conciencia nacional" y, por ello, se veía impelida por la generalidad de las circunstancias a rechazar la estatalidad como una entidad extraña. Una entidad, cuyos paradigmas ideológicos y organizacionales, lejos 
de representar una salida a la angustiosa situación vital y a la opresión que soportaba dicha población, sólo suponía un acoso para los arquetipos de pensamiento y de organización colectiva del mundo rural tradicional en el que se desenvolvían la mayoría de los latinoamericanos de entonces. En efecto, las leyes de Reforma y la generalidad de las estrategias económicas que adoptó el Estado liberal-oligárquico conllevaban un acoso para el grueso de las sociedades latinoamericanas de ese periodo, porque, en los casos en que no quedaron al margen del desarrollo ancladas en técnicas precapitalistas o semicapitalistas con bajísima productividad, dicho desarrollo significó para ellas una alteración sustancial de sus condiciones de existencia que además, en vez de implicar una mejora de los niveles de vida de la generalidad de la población, supuso un empeoramiento global de la situación de aquella. No sorprende pues que, con frecuencia, tales poblaciones rechazaran visceralmente la racionalidad jurídicoformal de la institucionalidad e ideología del Estado liberal y optaran por replegarse en la conservación y en la mitificación de los paradigmas de raigambre religioso-mitica que conformaban las bases sobre las que se legitimaba su identidad colectiva tradicional. Paradigmas que también, en determinados casos, constituyeron el substrato a partir del que se extrajeron simbologías colectivas para legitimar la protesta y la rebelión social; tal es el caso, por citar un ejemplo, de la utilización de la imagen de la Virgen de Guadalupe, en México, como estandarte de la sublevaciones campesinas acaudilladas por Hidalgo y Morelos, en la Independencia, $y$, posteriormente, en el movimiento zapatista durante la Revolución de 1910-17.

En sintesis, de lo que se acaba de señalar en los apartados "a", "b" $y$ "c" se desprende que la estructura social del periodo oligárquico se caracterizaba por tener una base económico-social bastante desestructurada y sectorializada, lo que, a su vez, estaba en paralelo con la escasa autonomía y capacidad, por parte del poder estatal, para planificar y gestionar la actividad económica; tarea esta, en la que aquel se encontraba subordinado a las exigencias de la oligarquía. Asimismo, los arquetipos básicos de legitimidad colectiva en este período no se correspondían con los de la racionalidad formal de la institución estatal, cuyo poder estaba, en consecuencia, débil o nulamente internalizado por la conciencia de la población y poco imbricado en la realidad social, a la vez que dependiente, en la práctica, de la buena marcha de las alianzas entre las distintas facciones que se repartian los poderes locales, sobre los que se apoyaba y 
sustentaba lo que, generalmente, no era más que una formalidad, una ficción de poder central con una reducida capacidad de maniobra.

Por otra parte, las condiciones de fuerte fragmentación y sectorialización económica del período oligárquico contribuyeron a obstaculizar la afirmación de una conciencia colectiva a nivel nacional. A todo ello se añadía la escasa legitimidad y representatividad social del Estado. Un Estado, cuya institucionalidad no llegaba a transcender, a escala nacional, los esquemas de las estructuras de poder, basadas en las alianzas familísticas, en el clientelismo caciquil y en las lealtades de carácter personalista, imperantes en el grueso de la estructura social. Estructuras de poder que constituyeron las bases sobre las que se sustentó la disgregación social caudillista, una de las principales motivaciones de las continuas guerras civiles que asolaron a las sociedades latinoamericanas durante una parte considerable del siglo XIX. Período este, en el que se puso de manifiesto como ninguno de los sectores oligárquicos en pugna logró eliminar a sus rivales a imponerse de una forma definitiva. A esta etapa inicial sucedió otra en la que, aunque siguieron en vigor las estructuras personalistas de poder, se consiguió una relativa consolidación del sistema de dominación oligárquico. Consolidación que se hizo posible cuando el Estado nacional se fortaleció lo suficiente como para ser capaz de imponer su arbitraje en las alianzas entre los sectores oligárquicos. Se trata de la época en la que, en Latinoamérica, los dictadores u“hombres fuertes" reemplazaron a los caudillos, a los que acabaron por someter a su poder.

\section{Los Populismos}

Se consideran incluidas dentro de esta denominación a modalidades de estructuración del poder, tales como el cardenismo mexicano, el varguismo brasileño o el peronismo argentino. Modalidades, entre las cuales existían bastantes y significativas diferencias, en las que no se considera pertinente entrar en esta exposición, que no pretende establecer tipologías exhaustivas al respecto, sino que, sobre todo, se encamina a poner de relieve, de acuerdo con el modelo que se viene empleando, las caracteristicas de la estructura social en torno a la que se conformaron las experiencias populistas.

a) El nivel económico-social. En realidad, el esquema de poder oligárquico y la estructura social en la que éste se sustentaba entraron en la crisis a raíz de 
la gran depresión económica de los años treinta. Tras la depresión se decidió dejar de lado el esquema liberal ortodoxo que, bajo el signo de la división internacional del trabajo, había encomendado a Latinoamérica el papel de prođuctora de materias primas (especialmente agrarias) para la exportación. Se optaba, a partir de entonces, por fomentar un decisivo movimiento de industrialización sustitutiva de importaciones, a las que se pusieron bastantes restricciones arancelarias. Una vez superadas las consecuencias adversas de la gran depresión ya no fue posible dar marcha atrás, pues, la industrialización habia permitido ir empleando con creciente productividad a una considerable parte de la fuerza de trabajo que en el modelo económico agroexportador había quedado al margen. Aunque los costes de la industrialización resultaron superiores que las importaciones que con ella se sustituían, el hecho es que cada vez se incrementaba más la oferta de trabajo, lo que, aunque nunca se alcanzara el nivel de suficiencia necesario para satisfacer por completo la demanda de empleo, conllevó un considerable incremento de la productividad y de los ingresos netos en el conjunto de la economía. Desde el punto de vista económico, las restricciones a las importaciones resultaron exageradas e incluso abusivas, pues, con tales medidas no se incentivó a la industria para mejorar sus técnicas de producción e ir adaptándose gradualmente a los niveles de competitividad internacional. De esta forma, se estaba, ya desde los propios inicios del proceso industrializador, sembrando el germen de las futuras crisis y brutales retornos a la ortodoxia del libremercado, que tan fatales consecuencias han tenido, en las décadas de los setenta y los ochenta, en lo relativo a propiciar el desmantelamiento de las obsoletas plantas industriales de determinados paises latinoamericanos.

Desde otro punto de vista, la industrialización propició el desarrollo de nuevas técnicas productivas y el requerimiento de más altos y especializados niveles de cualificación profesional, así como la irrupción de otras formas de organización social, burocrática e institucional, acordes con la creciente complejidad y especialización funcional de la sociedad que todo ello generaba. Nuevos grupos, tales como un creciente proletariado urbano-industrial y unas clases medias en alza emergieron al amparo de los procesos de urbanización y demás transformaciones que se estaban operando, a la vez que las oligarquías parecían en declive.

b) El nivel institucional. En el contexto económico-social que se acaba de describir, los populismos resultaron ser una peculiar modalidad de articulación 
del poder en la estructura social que fue, rápidamente, aprovechada por los sectores oligárquicos en retirada por esos años. A diferencia de la característica debilidad estatal del período oligárquico, durante el populismo el Estado asume un claro papel determinante, ampliando de forma considerable sus funciones como artifice del desarrollo económico y como organizador y dinamizador politico. Se llega así a constituir una especie de Estado paternalista, creador de empleo y fuente de servicios sociales, que funciona como un actor organizador de las masas, a las que incorpora a su proyecto atrayéndolas mediante el recurso a políticas de redistribución de la riqueza, tales como el establecimiento de subsidios al consumo popular o la seguridad social, En tanto que organizador de las masas, el Estado propicia la formación de grupos de base como sindicatos obreros, asociaciones de vecinos, sociedades asistenciales, etc. Todo ello, de cara a posibilitar la movilización social y la disponibilidad política de considerables sectores de la población, cuyo carácter policlasista y heterogeneidad se trata de integrarlos corporativamente en una conciencia común de reafirmación nacional. Conciencia esta que se procura desarrollar y fomentar a toda costa como contrapunto a la característica disgregación localista sobre la que se estructuraba el poder oligárquico.

c) El nivel simbólico-legitimador. Los regímenes populistas seguian teniendo, al igual que en periodo oligárquico, un carácter personalista y autoritario, pero su base de sustentación estribaba, especialmente, en el ejercicio de un liderazgo, más o menos carismático, sobre las masas. Sin embargo, el carisma del lider populista, a diferencia de la precaria estructura de poder en la que se asentaba por lo general el carisma del caudillo tradicional, se apoyaba en la creación, por parte del Estado, de complejas formas burocráticas de organización del poder político, asi como en la frecuente movilización de las masas que contribuía a la generación y al reavivamiento de dicho carisma. En el sistema de dominación oligárquico los paradigmas simbólico-legitimadores de la mayoría de la sociedad no coincidían con los inherentes a la ideología y a la institucionalidad del Estado, el cual se mantenía, al menos formalmente, sin necesidad de que sus débiles estructuras de poder estuvieran internalizadas por la generalidad de la conciencia colectiva de la sociedad. Una sociedad, habitualmente, muy fragmentada a nivel nacional y con unas estructuras de poder bastante sectorializadas, debido a la existencia, frecuentemente no armoniosa, de diversas facciones localistas. Sin embargo, en la etapa populista, 
la legitimación del poder estatal se lograba, básicamente, recurriendo a la movilización e incorporación de las masas a un proyecto de dominación, cuya fortaleza estribaba, sobre todo, en su característica capacidad para fomentar la adhesión de la población a sus proclamas y principios. Por su ascendente sobre las masas y su capacidad para fomentar y encauzar las movilizaciones, el líder populista propiciaba que, en tomo a su persona, se estructurase una forma de poder, cuya legitimidad dependía, en gran medida, de su capacidad para aglutinar a la diversidad de intereses y de tendencias inherentes al carácter policlasista de la sociedad. Una sociedad, en la que su alto nivel de desestructuración encontraba, de este modo, una ocasión coyuntural de ser superado en una síntesis integradora a escala del Estado-nación. Ocasión coyuntural porque, tan heterogénea agrupación de intereses, resultaba más viable en momentos de bonanza económica y de buenas expectativas para todos, pero, cuando sobrevinieron los tiempos de recesión y de crisis, los regímenes populistas, impelidos por no pocos sectores medios y altos que veían en la movilización de las masas una amenaza para su status quo, acabaron por frenar, recurriendo incluso a la represión, la estrategia movilizadora que ellos mismos habían impulsado originalmente como principal base de su legitimación. Estrategia movilizadora que, precisamente cuando empezaba a adquirir autonomía de acción y racionalidad política propias, comenzó a considerarse que no encajaba en la dinámica de la estructura đel pođer establecido, que podía resultar amenazante para el mantenimiento de un orden de cosas que, en lo fundamental, conservaba los privilegios de las oligarquías, contra cuyos intereses no se enfrentaron nunca a fondo los populismos.

En definitiva, de los antedicho se puede concluir que la estructura social del período de vigencia de los populismos experimentó, con respecto a la etapa oligárquica, sustanciales modificaciones que se patentizaron, sobre todo, en um incremento considerable del nivel de inserción del aparato institucional del Estado en la sociedad que, de este modo, aumentó notablemente su capacidad de intervención sobre la estructura social, así como de conformación y/o de modificación de la misma. En concreto, por lo que respecta al nivel simbólicolegitimador, los regímenes populistas seguían teniendo, al igual que en el período oligárquico, un carácter personalista y autoritario; pero, su base de sustentación estribaba, especialmente, en el ejercicio de un liderazgo más o menos carismático sobre las masas, las cuales eran oportunamente movilizadas 
e incorporadas al proyecto del Estado, mediante el impulso estatal de estrategias económico-sociales de carácter desarrollista y a través de políticas de orientación asistencialísta. Mecanismos estos que posibilitaban una oportunidad generalizada de mejora de las condiciones de vida de la población y, consiguientemente, un incremento considerable de los niveles de confianza $\mathrm{e}$ identificación colectiva de las masas con el poder estatal que, de esta forma, acrecentaba notablemente su grado de inserción en la estructura social.

\section{Del desbordamiento de las estructuras de poder populista a la brutali- dad represiva del militarismo contrainsurgente}

El carácter corporativista de los regímenes populistas y las políticas de conciliación de clases, en las que los mismos se sustentaron, repercutieron en que dichos regímenes fueran acabando por entrar en crisis, a medida que el desarrollo económico, por ellos mismos impulsado, evidenciaba las contradicciones de sus estructuras de dominación. En efecto, dicho desarrollo fue agudizando paulatinamente las desigualdades sociales y con ello se fue haciendo patente la necesidad, por parte de los elementos más conservadores de las oligarquías (que como se ha indicado antes sobrevivieron prácticamente intactos durante la vigencia de los populismos), de poner freno a las aspiraciones crecientes de unas masas, cuya dinámica reivindicativa había sido alimentada, en un principio, precisamente por los gobiemos de carácter populista, que ahora no dudaban en recurrir a la represión. Ante esta situación, se comprende la opción por la lucha armada (especialmente, en las décadas de los sesenta y setenta) de diversos movimientos sociales que creyeron encontrar en su particular interpretación del marxismo unas alternativas utopico-revolucionarias, frente a las limitaciones estructurales que imponían los sistemas establecidos para satisfacer sus deseos de cambio real, a la vez que de mejora de las condiciones de vida de la mayorías latinoamericanas, inmersas en una estructura social profundamente inequitativa e injusta.

a) El nivel económico social: del proteccionismo al neoliberalismo o la opción por los extremos. En este periodo se inició la puesta en práctica de las políticas "neoliberales" que han continuado después aplicándose durante los regímenes democráticos. He puesto la expresión neoliberal entrecomillada porque considero que hay que precisar que, en realidad, el tan pregonado retomo 
a la ordoxia clásica heredera de la obra teórica de Adam Smith se concreta, sobre todo, en la liberalización de aspectos como la protección social, fomentándose, en cambio, la intervención del Estado en variables macroeconómicas, tales como las que inciden en las fluctuaciones monetarias. Todo ello, en consonancia con las directrices e intereses de organismos como el Fondo Monetario Internacional(F.M.I.) o el Banco Mundial. Organismos estos, cuya tradicionalmente decisiva influencia se ha visto hoy especialmente incrementada a raíz del derrumbe del llamado "socialismo real", dada la consiguiente pérdida de legitimidad de cualquier tentativa de regulación de los aspectos productivos y distributivos de la economía que de esta situación se ha derivado.

Lo cierto es que, como ya dije antes, la marcada orientación proteccionista del populismo no incentivaba la mejora de la competitividad. ¿Que interés podían tener las débiles y acomodaticias burguesías industriales latinoamericanas de entonces en modernizarse y hacer más eficaces sus métodos productivos, si contaban de antemano con un mercado garantizado para sus productos?.

Digo todo esto porque, a fin de cuentas, la política neoliberal todavía en boga en la actualidad, busca su justificación, en gran medida, en los efectos perversos del proteccionismo del periodo anterior. Asi pues, resulta que debido a éstos y a otros efectos perversos se viene optando, a escala mundial, desde hace unos años por una liberalización progresiva, incluso de los sectores económicosociales básicos. De este modo, las políticas neoliberales se han acabado por convertir en una receta aplicada por sistemas tanto de izquierdas como de derechas. Receta puesta en práctica incluso por los regímenes del "socialismo real" aún en pie, como es el caso de China, en la que tales políticas económicas se conjugan con la perpetuación de la "dictadura sobre el proletariado"; con toda probabilidad, para evitar perder el control del proceso y que les suceda algo semejante a lo acaecido en la extinta Unión Soviética. Pero, en fin, no es objeto de este trabajo analizar lo acontecido con los sistemas comunistas.

La realidad es que los humanos funcionamos de acuerdo con unos comportamientos sujetos a lo que yo đenominaría como la "ley đel péndulo"; es decir, pasamos de un extremo a otro. De acuerdo, el proteccionismo tenía inconvenientes como la ya señalada falta de incentivos para mejorar los niveles de competitividad. Lo que sucede es que, al poner en práctica recetas neoliberales y levantar las barreras arancelarias, aquellos productos que son más competitivos y/o más baratos acaban por desbancar a los que son menos, ya que las 
infraestructuras destinadas a producir éstos entran en crisis $y / 0$ tienden a ser desmanteladas. En concreto, para las obsoletas y escasamente competitivas infraestructuras productivas latinoamericanas, el neoliberalismo ha resultado especialmente problemático y amenazante, de tal forma que, en los casos en que no han sido prácticamente desmantelados determinados sectores de tales infraestructuras, éstos entraron en una profunda crisis que aún continúa.

A mi modo de ver, y conste que no soy economista (o precisamente por ello), la solución menos costosa desde el punto de vista social (y por ende económico) es aquella que no se orienta ni por el proteccionismo a ultranza (favorecedor del mantenimiento del status quo y de la desincentivación de la búsqueda de la competitividad) ni por romper de pronto todas las barreras arancelarias. El problema es como se conjuga una política de alicientes para mejorar la competitividad productiva con el proteccionismo, ineludible para propiciar el despegue económico de los países menos desarrollados.

Especificamente, en el ámbito latinoamericano, las directrices neoliberales han tenido consecuencias concretas como una tendencia progresiva a ir privatizando cađa vez mayores áreas del sector público de la economfa, una reducción gradual de los gastos destinados a cometidos como la sanidad, la educación o la asistencia social en general, una creciente precarización del empleo y de las condiciones de trabajo, considerables reducciones relativas de los salarios y de la capacidad adquisitiva de los trabajadores en una época de inflación ascendente, aumento paulatino de los ya de por sí muy significativos niveles de pobreza y/o de marginación social, etc., etc. Los potenciales factores de conflicto y de malestar social que todo esto constituía sólo pudieron ser atajados, en un principio, mediante la brutal represión, articulada a través del aparato institucional del Estađo, que se puso en práctica en las dictaduras.

b) El nivel institucional. Lo cierto es que en los regímenes militares se seguian conservando los rasgos verticalistas y autoritarios de las estructuras del poder estatal que, en el presente texto, se han concebido como característicos de estructuras sociales tan fragmentadas y localistas como es el caso de las latinoamericanas. Sin embargo, tales rasgos verticalistas y autoritarios se elevaban entonces a su más alta y perniciosa expresión. De este modo, en las dictaduras militares el poder encarnado en el aparato institucional del Estado fue instrumentalizado de una manera tan virulenta y terrible como desprovista, por completo, de toda garantía de control mínimamente democrático, por parte de 
la inmensa mayoria de la población que hubo de soportar esta forma de dominación.

En todo el mundo y en todas las facetas de los órdenes humanos hay una dicotomia, más o menos pronunciada, entre lo "oficialmente" proclamado ylo que de verdad se hace, entre los discursos y las prácticas. Pero, en el caso de los regímenes políticos latinoamericanos, esta dicotomía es especialmente grande. Así, una característica constante de tales regímenes es el profundo abismo existente entre lo formal u oficialmente proclamado y establecido (por lo general acorde con los planteamientos republicanos liberal-democráticos) y la realidad sociopolítica vivida, en la que siempre han existido fuertes obstáculos político-estructurales para el desarrollo de cometidos democráticos tan elementales como el ejercicio individual y colectivo de la libertad de expresión y de asociación o para la adopción de estrategias tendentes a desarrollar unas condiciones de igualdad, tanto en lo económico-social como en lo que se refiere a la participación en las tareas públicas que conciernen y/o afectan a la población.

Con las dictaduras se ahonda más que nunca, en Latinoamérica, el abismo entre la formalidad politica oficial y la realidad vivida por la mayor parte de la población en esos años. Una realidad de terror, de continuas y masivas desapariciones, torturas y ejecuciones extrajudiciales que coexiste, generalmente, con el no desmantelamiento de una considerable parte del aparato juridico-institucional del Estado vigente en otros periodos. De este modo, la institucionalidad estatal queda reducida a una mera formalidad, a una representación esperpéntica, que ni siquiera llega, por lo general, a reconocer públicamente la situación brutalmente represiva en la que se apoya la política económico-social adoptada en esos años. Sólo así se explica el empeño oficial, habitual en ese periodo, pornegar la evidencia de la represión y/o por el recurso casi sistemático a procedimientos extrajudiciales. Silenciamiento del terror que, gracias al empecinamiento y a la valentía de muchos héroes y heroínas más o menos anónimos (como, por ejemplo, las Madres de la Plaza de Mayo en Argentina), fue poco a poco siendo desenmascarado.

Hay quienes han caracterizado a estas dictaduras como regímenes fascistas. La verdad es que el fascismo y el nazismo, al menos en sus iniciales procesos de ascenso al poder, llegaron a propiciar determinadas modalidades de movilización social (aunque perfectamente controladas e instrumentalizadas) y 
a articular un cierto sistema ideológico-institucional de racionalización y de legitimación de su totalitarismo sociopolítico, así como de sus actuaciones represivas. Actuaciones justificadas, desde luego, con presupuestos tan discutibles como la pretendida supremacía de la raza aria o la necesidad de erigirse en garantes de un orden social amenazado.

En cambio, la tarea represiva llevada a cabo por las dictaduras latinoamericanas manifestó un especial interés en encubrir sus actos, los cuales fueron ejercitados, en su mayoria. hipócrita y subrepticiamente al margen de la institucionalidad jurídico-normativa oficialmente establecida, reducida, de este modo, a una simple formalidad. Institucionalidad jurídico-normativa que, desde luego, fue cómplice, en mayor o menor medida, de que permaneciera en la impunidad la sistemática y atroz represión llevada a cabo en esos años

c) Elnivel simbólico-legitimador. Una de las justificaciones, más usualmente esgrimidas, para explicar el recurso a la dictadura, enla década de los setenta y primera parte de la de los ochenta, fue la supuesta existencia de una ineludible necesidad de emprender una guerra contra la "insurgencia y la subversión marxistas", las cuales se consideraba que amenazaban seriamente la seguridad nacional de los países latinoamericanos y la pervivencia de sus pretendidos sistemas democráticos. En realidad, la doctrina de la seguridad nacional (d.s.n.), que ha desarrollado toda una tradición teórico-ideológica en el contexto latinoamericano, ha estado siempre presente en la conformación y en la legitimación de los regímenes de esta región geopolítica del mundo. Lo que sucede es que, en las dictaduras militares, la d.s.n. manifiesta sus rasgos y comportamientos característicos con una especial intensidad y virulencia.

Combatir la insurgencia y la subversión marxista, paradójica y terrible forma de entender la conservación de la democracia y la garantía de la seguridad nacional, que, de hecho, implicó que, en esos años de generalizado terror colectivo de las dictaduras, se viera seriamente amenazada la seguridad existencial de una gran mayoría de la población latinoamericana, ya sea por la fuerte represión a la que se vio sometida, ya por la paulatina depauperación de su situación socioeconómica como efecto de las políticas neoliberales entonces emprendidas.

Con la tipificación de subversiva se llegó a catalogar, incluso, cualquier manifestación de auténtica libertad de acción o expresión de protesta social. Por pacífica y elemental que dicha protesta fuera, era reprimida con el mismo 
énfasis y métodos violentos que si se tratara de una insurrección armada contra el sistema. De ahi, que las dictaduras militares puedan ser conceptuadas como una de las expresiones más brutales de la hegemonización, autoritaria y fatalmente represiva, por parte de los elementos más conservadores y reaccionarios de la sociedad, del aparato del Estado. En realidad, el propósito de esta represión sistemática, que puede ser conceptuada como un auténtico terrorismo de Estado, era no solamente combatir la insurgencia, sino además, suprimir de ráz toda expresión de descontento, de crítica o de oposición. Desde cierto punto de vista, puede afirmarse que se pretendía paralizarmediante el miedo cualquier tentación de disidencia individual o colectiva ante la crisis y malestar social que estaba desencadenando la aplicación de las políticas económicas neoliberales.

\section{Estructuras sociales y estructuras de poder en las actuales democracias}

La extrema brutalidad y la barbarie de las dictaduras militares, conjuntamente con la crisis socieconómica derivada de la ortodoxia neoliberal de la política económica por ellas adoptada son los factores principales de su caída. Al mismo tiempo, dichos factores constituyen las más importantes garantías contra las tentativas de involución autoritaria en la actualidad. Por otra parte, conviene hacer notar que, en granmedida, la fragilidad de las actuales democracias deriva de la incapacidad del poder estatal para imponer y emprender políticas que posibiliten una salida de la caótica situación económica y social en la que se encuentran sumidos los países latinoamericanos. Especialmente, tal falta de autonomía se debe a la ingente e impagable deuda externa.

Algunas de las que yo considero limitaciones estructurales internas más destacadas, con las que se tropiezan los Estados tatinoamericanos de hoy, a la hora de plantearse la adopción de estrategias tendentes a superar la profunda crisis económica, política y de legitimidad en la que se encuentran sumidos, se hacen evidentes sólo con constatar la persistencia de sus tradicionales características en las actuales estructuras sociales latinoamericanas, las que continúan siendo concebidas, en el esquema que sigue, teniendo en cuenta los tres niveles, económico-social, institucional y simbólico-legitimador/con los que se definió el modelo de estructura propuesto al principio de estas argumentaciones. 


\section{CARACTERISTICAS MÁS SOBRESALIENTES DE LAS ACTUALES ESTRUCTURAS SOCLALES LATINOAMERICANAS}

\section{a) Niveleconómico-social:}

- Ausencia de una clase media fuerte.

- Profundas desigualdades sociales y rigideces que obstaculizan la movilidad (son sociedades de casta/clase).

- Miseria colectiva muy extendida.

\section{b) Nivel Institucional:}

- Frecuentes corruptelas, crisis e ineficacia generalizada de las instituciones burocrático-estatales, con la consiguiente desconfianza de la población respecto de las mismas.

- Escasez, cuando no ausencia, de cauces institucionalizados de negociación, de canalización y de expresión de las demandas colectivas.

- Localismo y fragmentación social en la distribución del poder, lo que, habitualmente, provoca conflictos entre distintas visiones personalistas de los asuntos nacionales.

c) Nivel simbólico-legitimador:

- Reiteradas crisis de identidad nacional.

- Proliferación de sentimientos colectivos de indefensión y de desorientación generalizados.

- Escasa implantación social de los valores y simbologías legitimadoras de la racionalidad de la cultura política, cuyo bajo grado de internalización colectiva es patente.

El esquema anterior muestra que las estructuras sociales de los paises latinoamericanos difieren, notablemente, de las que propician el asentamiento yla consolidación de los regimenes democráticos en las sociedades industriales avanzadas. En éstas se ha producido una institucionalización de los conflictos y de las relaciones entre el Estado y la sociedad con un grado de estructuración tal que posibilita que se produzca un alto nivel de imbricación de las estructuras del poder estatal en su entramado económico e institucional y en su identidad colectiva. El Estado en tales sociedades se aproxima mucho a la concepción que Emile Durkheim tenía del mismo. En efecto, para Durkheim el aparato estatal, en realidad, no ejecuta nada sino es por delegación de la sociedad. Esta sería 
equiparable para él al sistema nervioso, mientras que el Estado equivaldría simplemente al sistema muscular.

En cambio, en los países latinoamericanos, el modelo de estructura de poder del Estado que se necesita está más próximo a la concepción que del mismo tiene Max Weber. Para éste, el Estađo constituye más bien un grupo de personas que reivindica para sí (con éxito) el monopolio del empleo legítimo de la violencia dentro de un territorio determinado. El carácter decisionista (en el sentido de decidir sobre y/o acerca de otros, de imposición de la voluntad de un grupo al resto de la sociedad) que Weber destaca como inherente al poder estatal encuentra, en el contexto latinoamericano, unas condiciones estructurales óptimas para su corroboración. En efecto, las estructuras sociales latinoamericanas han sido y continuan siendo profundamente contradictorias, en lo económico y en lo social, a la vez que muy fragmentadas y heterogéneas a nivel simbólico-legitimador. De ahi, que tales estructuras sigan propiciando circunstancias potencialmente favorables para el surgimiento y la proliferación de estrategias de poder estatal, cuando no carismáticas y/o personalistas, al menos de corte autoritario o verticalista. De ahí también, que dichas estructuras reclamen la existencia de un Estado fuerte, en condiciones de decidir y de actuar económica y políticamente con un, relativamente alto, margen de autonomía y apto para conformar una estructura de poder capacitada para integrary vertebrar a la diversidad de facciones y de tendencias, inherentes a la caracteristica inclinación latinoamericana al localismo y/o a la fragmentación. Un Estado, además, con capacidad y voluntad de resolver los problemas de alimentación, vivienda, salud, educación y cultura experimentados por la mayoria de una población que, consiguientemente se ve impedida de ejercer su libertad y, por lo tanto, de convivir democráticamente. Se trata, pues, de hacer posible que la institucionalizar estatal se oriente a materializar las condiciones de existencia de la democracia, asi como, al acrecentamiento, en gran medida mediante la puesta en funcionamiento de cauces de negociación y de arbitraje, de las posibilidades institucionales de regulación de los conflictos, derivados de las numerosas y profundas contradicciones y desigualdades socio-económicas que. siguen estando vigentes en las estructuras sociales latinoamericanas. Todo ello, porque creo que conferir un alto grado de autonomia al poder estatal no tiene porque implicar, necesariamente, ni el paternalismo populista ni una restricción de las posibilidades para el ejercicio y el desarrollo de la democracia, la cual, 
considero que ha de ser planteada como una exigencia irrenunciable para América Latina, comola única alternativa sensata después de prolongados años de enfrentamientos estériles y de radicalismos de uno y otro signo ideológico.

El reto está, por lo tanto, en reflexionar para encontrar fórmulas de organización político-institucional que permitan compaginar la necesidad de un fuerte carácter decisionista de la estructura de poder de donde emana la autoridad estatal con el respeto a los derechos humanos, a las libertades de asociación y de expresión básicas y otros prerrequisitos imprescindibles para garantizar la convivencia democrática. Ello, porque, en la medida en que dicha convivencia quede en efecto asegurada, estará realmente en manos de la voluntad de las mayorias populares latinoamericanas la facultad de decidir sus destinos, $\mathrm{o}$, đicho más concretamente, podrán determinar por vía electoral o por cualquier otro de los mecanismos que las organizaciones democráticas establecen al respecto, el carácter, más o menos progresista o conservador, de ese Estado que se ha postulado a lo largo de este texto como necesariamente verticalista y/o intervencionista. 


\section{Pibliografía}

El presente texto constituye un intento de extrapolar a la totalidad latinoamericana el modelo de análisis empleado en la realización de mi tesis doctoral. Dicha tesis, que fue dirigida por los Doctores de la Universidad Complutense de Madrid D. Carlos Moya Valgañón y D. Ramón Ramos Torre, versó sobre "Caudillaje y Estructura Social en México" y fue defendida en dicha Universidad en enero de 1986. Por otra parte, aunque no he seguido, explícitamente, ninguna obra a la hora de elaborar este escrito, deseo manifestar mi reconocimiento a Jorge Graciarena y a Rolando Franco por su obra Formaciones sociales y estructuras de poder en América Latina. Centro de Investigaciones Sociológicas (C.I.S.), Madrid, 1981. Asimismo, creo conveniente incluir, solamente con el fin de orientar a los lectores no conocedores del tema, la siguiente bibliografia acerca de la situación económica, social y política latinoamericana.

ALCÁNTARA SAEZ, M. (1989), Sistemas politicos de América Latina, Madrid, Ed. Tecnos.

CARRANZA, M.E. (1978), Fuerzas armadas y Estado de excepción en América Latina, Madrid, Siglo XXI de editores.

CENTRO ESPAÑOL DE ESTUDIOS DE AMÉRICA LATINA (C.E.D.E.A.L.), edita bimestralmente unos informes en torno a la coyuntura económica y politica latinoamericana. A simismo, esta institución ha publicado, en su "serie Estudios", diversos trabajos acerca de temas como: a) Evolución macroeconómica y políticas de ajuste, b) El problema de la financiación externa, y c) Cambio político y transición democrática. Dicho centro está ubicado en Madrid en Avđa. Reyes Católicos, núm. 4, planta 5a, Distrito postal 28040.

CHEVALIER, F.(1979), América Latina. De la Independencia hasta nuestros dias, Barcelona, Ed. Labor S.A.

COMBLIN, J. (1978), El Poder Militar en América Latina, Salamanca, Ed. Sígueme.

ENTRENA DURAN, F. (1990), Caudillaje y Estructura Social en México, Madrid, Ed. Universidad Complutense.

ENTRENA DURAN, F. (1992), La estabilidad mexicana y la crisis de los regimenes politicos en América central, Madrid, Ed. Akal. 
ENTRENA DURÁN, F. (1990), La formación del Estado en México (18211911), Madrid, C.D.E.A.L.

ENTRENA DURAN, F. (1989), Revolución y Construcción del Estado en México, Revista Quinto Centenario, num. 15.

FERNANDEZ FRANCO, L, (1990), La doctrina de la seguridad nacional en América Latina. El caso Brasileño, Tesis doctoral presentada en la Universidad Complutense de Madrid.

IANNI, O. (1975), La formación del Estado populista en América Latina, México, Ediciones Era.

IONESCU, G. y GELLNER, E. (Comps), (1969), Populismo. Sus significados y características nacionales, Buenos Aires, Amorrortu Editores.

LAMBERT, J. (1978), América Latina. Estructuras sociales e instituciones politicas, Barcelona. Ed. Ariel.

LITTUMA, A. (1967), Doctrina de la seguridad nacional, Caracas, Ministerio de Defensa.

MERCADO JARRIN, E. (1979), La seguridad nacional y la Constitución, Revista del Instituto Peruano de Estudios Geopoliticos y Estratégicos (IPEGE), Lima.

MORALES PADRÓN, F. (1972), Historia de Hispanoamérica, Universidad de Sevilla.

RAMA, C.M. (1977), Sociologia de América Latina, Barcelona, Ediciones Península.

ROITMAN, M. y CASTRO GIL, C. (coordinadores), (1990), América Latina entre los mitos y la utopia, Madrid, Ed. universidad Complutense.

SOTELO, I. (1972), Sociología de América Latina. Estructuras y problemas, Madrid, Ed. Tecnos.

TAPIA VALDÉS, J.A. (1980), El terrorismo de Estado. La Doctrina de la Seguridad Nacional en el Cono Sur, México, Ed. Nueva Imagen.

VARIOS, 2 tomos, (1986), Sistemas electorales y representación politica en Latinoamérica, Madrid. Ed. Fundación Friedrich Ebert e Instituto de Cooperación Iberoamericana. 